\title{
Flickr: organizing and tagging images online
}

\begin{abstract}
Flickr was launched when digital cameras first began to outsell analog cameras, and people were drawn to the site for the opportunities it offered them to store, organize, and share their images, as well as for the connections that could be made with other likeminded people. This article examines the links between Flickr's success and how images are organized within the site, as well as the types of people and organizations that use Flickr and their motivations for doing so. Factors that have contributed to Flickr's demise in popularity will be explored, and the article finishes with some suggestions for how Flickr could develop in the future, along with some conclusions for image organization.
\end{abstract}

\subsection{Introduction}

Flickr (www.flickr.com) - from the English word 'flick', meaning to flick through something - is an image- and video-hosting website that was launched in 2004 by Stewart Butterfield and Caterina Flake. Whilst Flickr's creators originally intended for it to be a massive multiplayer online game (called Game Neverending), it was the image sharing aspect of the game that unexpectedly became more popular, and so the original game idea was abandoned, thus allowing for the development of Flickr.

Flickr is credited as being one of the 'first classic web 2.0 sites' (Van House et al. 2005; Cox 2008a; Cox, Clough and Siersdorfer 2010) as it provided the perfect mix of new and innovative features that piqued people's interest at a time of significant change on the web. This change became known as web 2.0, and the term was widely used from 2004 up until around 2008 (Google Trends 2018) to refer to a fundamental shift in the way that people created and shared information online. Rather than being passive consumers of information on websites, the consumers themselves now began generating the content for websites such as YouTube (videos), Wikipedia (collaborative articles), and Twitter (thoughts and ideas). Similarly, with Flickr, it was the users of the website itself who generated the content (i.e., the images), and they were drawn to the site because of the innovative new features if offered such as the use of photostreams, tags, favorites, and groups (McCracken 2014). Flickr also provided a platform for people who were passionate about photography to share their images with other people who were also passionate about photography at the exact same time that digital cameras first began to outsell analog cameras (Weinberger 2007, 12). Thus, a new knowledge organization system was born, creating a place for the management and retrieval of people's images. The timing for Flickr was perfect, and it soon became 'one of the internet's biggest repositories of photographs' (Wray and Johnson, 2008), thus making it an important digital cultural repository to explore and evaluate.

At the height of its popularity in around 2010, 3,000 images were being uploaded to Flickr every minute (Flickr 2010), which equated to approximately 4.3 million images each day. It was a website that rode the web 2.0 wave extremely successfully, continually adding new features and listening to feedback from users, and it was always more popular than rival photo hosting sites such as Picasa, Photobucket, SmugMug, Shutterfly, and Photoshelter.

However, Flickr's heyday now seems to be over, with the most recent statistics being released by Flickr in 2014 stating that only 1 million images were now being uploaded each day (Etherington 2014). Flickr's decrease in popularity seems to be the culmination of three main factors. Firstly, Flickr was acquired by Yahoo in 2005, and whilst the acquisition did not immediately cause adverse effects for Flickr, Stewart Butterfield (one of Flickr's creators) nonetheless admits that Yahoo stifled innovation within the company, and he dramatically resigned in 2008 (Kim 2014), thus indicating that all was not well in the Flickr/Yahoo partnership. Secondly, Flickr's failure to implement a successful mobile platform (Bowker 2017). And lastly, the rise of image-centric smartphone applications such as Instagram and Snapchat have usurped a large amount of attention away from Flickr (Bowker 2017). 
This article will explore in more depth the links between Flickr's success and how images are organized within the site, as well as the factors that have contributed to the site's decrease in popularity, and how Flickr may adapt in the future to keep pace with a changing knowledge organization landscape.

\subsection{Success and knowledge organization in Flickr}

For a knowledge organization system to be accessible and usable, the knowledge contained within it has to be organized in some way (Soergel, 2009). With Flickr, it is the users of the system itself that organize the digital images, and this is one of the site's main success factors. In the context of Flickr, digital images are defined as, 'a representation of an image stored in numerical form, for potential display, manipulation or dissemination' (Terras 2008, p.6). The default view of images once uploaded in Flickr is the 'photostream'. A user's photostream displays all of their images sorted by upload date, with the most recently uploaded images at the start of the stream (Wilkinson 2007). Other users can follow photostreams by clicking a follow button whilst viewing a person's image, and such follows tend to be reciprocated (Mislove et al. 2008). Images in Flickr can also be organized into sets and groups, based on whatever concepts users like (Stuart 2013). A set is a collection of images from a user's photostream, and users tend to add images with a common theme into sets (e.g., images from a specific event or holiday). For personal information organization using traditional photo albums photographs could only exist in one place at a time, whereas digital images can be placed in any number of Flickr sets at once. Images can also be placed into groups, where 'like-minded users gather, discuss things, and share pictures' (Wilkinson 2007). Images can also be 'favourited' by other users, and users can monitor statistics on the number of times their images have been viewed.

In addition to images being placed into sets, albums and groups, images can also be categorized according to what Berinstein (1996, p. 26) calls the visual and non-visual attributes of an image. The non-visual attributes of an image relates to its biographical elements, and in Flickr this equates to metadata that is embedded in images that have been taken with digital cameras. Metadata is 'data about data', and for digital images this can include information such as: the date and time that the image was taken; the make and model of camera or cameraphone used; shutter speed; specific settings that were used; focal length; and even GPS data (Bausch and Bumgardner 2006). This type of metadata can be useful in two main ways: to help you remember how you achieved a shot that you are particularly proud of and may want to try to recreate; and it also tells other users how they can achieve a similar effect for their images (Bausch and Bumgardner 2006).

The visual attributes of an image can relate to either the subject content of an image (i.e., what the image is of or about), and it can also relate to object aspects such as colour, shape, perspective, composition, pattern etc. Whilst a person may add descriptors to their images that relate to attributes such as colour, shape, pattern etc, these attributes are more commonly associated with content-based image retrieval (CBIR) where images are retrieved using automated systems that search at pixel level (Jansen 2008, p. 82). Flickr offers a similarity based filter when searching for images and it also allows you to filter images by style, and pattern. The subject content approach to categorizing and classifying an image tends to be based on what an image is of and about, and there is no standardized protocol for achieving this (unlike books, which can all be categorized according to, for example, the Dewey Decimal System). As such, a number of different approaches have been developed. One approach is called subject indexing (Graham 2001). This approach involves assigning terms to images that have been selected from a controlled vocabulary such as a subject heading list (e.g., the Library of Congress Subject Headings); a thesaurus (e.g., Art and Architecture Thesaurus (AAT) or the Thesaurus for Graphic Materials (TGM)); or a classification scheme (e.g., ICONCLASS) (Graham 2001). 
The main drawback with the use of such systems is that they can only be used by subject specialist professional indexers, with it typically taking up to 40 minutes to assign terms to one image (Eakins and Graham 1999), and the terms that are attached to images are often far removed from the retrieval needs of the end users. Whilst this was not a problem with traditional analogue picture libraries where images would be retrieved by staff for the end users, it is however more of a problem with web-based image databases where it is the end users themselves that search for the images they want. However Flickr does not utilize controlled vocabularies, thesauri, or specific classification schemes as it is not generally subject specialist professional indexers that are attaching key terms to the images on Flickr, it is normal everyday people. Shirky (2005) describes this change as heralding a philosophical shift in indexing, and Rafferty and Hidderley (2007) describe it as a shift from a monologic to a dialogic indexing practice.

It is widely accepted that images are inherently more difficult to categorize than text, as, 'a picture can mean different things to different people, and it will also mean different things to the same people at different times' (Graham, 2001). However, as the person who creates the image is generally the person who uploads it to Flickr, they are not therefore likely to struggle in deciding what key terms should be attached to their image. However, the key terms chosen by the image creator are not necessarily the same key terms that other end users will subsequently use to search for images with in Flickr. This can be seen as one of the main problems on a user-generated site such as Flickr.

With Flickr being credited as 'one of the Internet's biggest repositories of photographs' (Wray and Johnson, 2008), Morville (2005) reiterates that findability is a key issue in a busy information environment and the main method of both categorizing and subsequently retrieving images on Flickr is via the use of user-generated tags (Wilkinson 2007).

\subsection{Tagging and image retrieval}

One of the main facets of knowledge organization, is the process by which knowledge is organized, such as abstracting, indexing, cataloging, subject analysis, and classifying. The process of tagging can now also be added to this list. Whilst tagging was introduced in 2003 by a now discontinued social bookmarking website called Delicious (Cagnazzo 2018), Flickr was one of the first websites to fully adopt tagging and make it mainstream (Smith 2008, 9). Tagging is seen as one of the most successful phenomena generated by web 2.0 (Cagnazzo 2018). Tagging is the name given to the process whereby users assign keywords to web objects (Xu et al. 2006), and whilst tagging is not mandatory in Flickr, it is the main method for allowing images to be subsequently retrieved by other users, and images can have one or more tags assigned to them.

Tagging is a key part of the organizational structure on Flickr (Wilkinson 2007) and tags essentially organize, describe, comment on, and categorize resources, thus allowing the images to be retrieved at a later date. If a person tags all the images in their photostream that contain a sunset with the tag 'sunset', then when they subsequently click on the tag 'sunset', all their images of sunsets will be displayed to them, tags therefore act as links (Bausch and Bumgardner 2006). Similarly, a person may perform a global search within Flickr, and find images by all users that have been tagged with 'sunset'. Although there is no way of ultimately knowing if all relevant images have been retrieved. Whilst it is possible to add tags to another user's images (social/collaborative tagging), this has not proved to be a popular practice in Flickr (Marlow et al. 2006; Cox 2008a; Ding et al. 2009), presumably because images (especially if the images are photographs of friends or family) are regarded as quite personal items. In a social system such as Flickr, tagging can also be a means of attracting traffic to one's images (Zollers 2007), thus facilitating interaction between users.

Unlike traditional classification and indexing, tagging is not hierarchical, although some systems may adopt the use of automatically generated related tags (Rafferty 2016). Flickr did introduce an auto-tagging feature in 2015, however the tag suggestions were based on image recognition technology (i.e., analysis of the visual features within the image) 
rather than semantic relationships between words associated with the image. The autotagging feature received much controversy after images of black people were automatically given the tags 'ape' and 'animal' (Hern 2015).

Rorissa (2010) conducted a study to empirically test the similarities and differences between user-generated tags assigned to images on Flickr compared to controlled vocabulary assigned to images in general image collections by professional indexers. Overall it was found that there were significant differences between the two groups, and that user-generated tags and controlled vocabularies tend to have different underlying structures. Jörgensen (2003) points out that whilst controlled vocabularies can help to guide users to select appropriate terms to assign to their images, they nonetheless have a number of drawbacks, including the fact they tend to be narrow, expert-oriented vocabularies that use inflexible and pre-coordinated terms.

There is an extensive body of research that has suggested that tagging is utilized on Flickr for a combination of four main reasons, two of which centre around concepts of knowledge organization (i.e., social-organization and self-organization), and the other two centre around concepts of communication (i.e., social-communication and selfcommunication) (Van House et al. 2004; Van House et al. 2005; Van House 2007; Nov, Naaman and Ye 2009a; Nov, Naaman and Ye 2009b; Ames et al. 2010). Socialorganization is where tags are utilized so that other users of Flickr are able to search for and retrieve images. Self-organization is using tags to categorize images to make it easier for oneself to find them in the future. Social-communication is whereby tags are used to express emotions or opinions, or to attract attention to images. Self-communication is the use of tags to aid with one's own memory of events and for personal reflection.

There have been numerous studies that have looked at the types of tags that Flickr users apply to their images. Sigurbjörnsson and van Zwol (2008) found that in a collection of over 52 million publicly available Flickr images, user's tags tended to describe the where (an image was taken), the who or the what (is in the image), and the when (the image was taken). It was also found that the top 5 most frequently occurring tags were: 2006, 2005, wedding, party, and 2004. This finding suggests that tags in Flickr tend to follow a power law distribution whereby the majority of images are annotated with the same few tags (Mathes 2004; Sigurbjörnsson and van Zwol 2008).

In an analysis of 1.4 million Flickr tags Ding et al. (2009) found that the most popular types of tags were dates, locations, colours, and seasons. However, Flickr users are rarely found to have more than 20 tags assigned to their images (Barton 2015, 54). Whilst Flickr has a global userbase, people tend to consider the wider Flickr community when tagging their images and generally opt to tag in English, which is less likely to exclude other users (Dotan and Zaphiris 2010).

Research on tagging has highlighted numerous weaknesses with its use, which ultimately mean that the knowledge organization systems that adopt tagging have certain limitations, including: misspellings and nonsensical tags (Aurnhammer et al. 2006; Guy and Tonkin 2006; Spiteri 2007); ambiguous and personalized tags (Guy and Tonkin 2006; Macgregor and McCulloch 2006); compound tags (Mathes 2004); tags that utilize abbreviations, initialisms and acronyms (Spiteri 2007); tags that use neologisms, slang, and jargon (Spiteri 2007); and polysemous words, synonyms, homonyms, and homographs (Aurnhammer et al. 2006; Golder and Huberman 2006).

All of these issues have led to criticism and the conclusion that tags impact negatively on retrieval precision (Macgregor and McCulloch 2006). On the flipside however, it is also said that all of these issues contribute towards a true representation of knowledge (Macgregor and McCulloch 2006), and a rich end-user vocabulary (Rorissa 2010) and Spiteri (2007) suggests that the percentage of 'problem tags' is actually very small. The adoption of semantic tagging (tagging content with URIs) is now seen as a way of overcoming some of the problems inherent with user-generated tags (Cagnazzo 2018). 
Other research has suggested that tags are often more closely related to the motivation of the uploader, rather than relating to image content (Kennedy et al. 2007), with motivation to tag often being very different from the initial motivation to use a website (Stuart 2012), and people may also have more than one reason for tagging (Ames and Naaman 2007). Much of the literature on motivation for tagging distinguishes between tagging for one's own organization and retrieval purposes or tagging so that other people are able to find the content in question (Hammond et al. 2005; Marlow et al. 2006; Heckner, Heilemann and Wolff 2009). In an investigation of motivation to upload and tag images in Flickr which included a sample of 3,462 images and 12,832 tags, it was found that overall motivation to upload and tag images was not related to the types of tags that users subsequently assigned to their images (Stuart 2012). Tags that generically described what images were 'of' were found to be the most popular type of tag category (Stuart 2012).

Geotagging is also an additional way of being able to tag images in Flickr, which is where latitude and longitude coordinates are attached to an image, thus allowing for exact geographical identification (Bausch and Bumgardner 2006).

Images in Flickr can also have titles and descriptions added to them, which can also aid in their retrieval. Titles are generally just a few words long and appear above an image, whereas descriptions appear below an image, and can be anything from a few sentences to an entire story about the image in question (Bausch and Bumgardner 2006). Whilst it is the tags, titles and descriptions that are attached to images that allow them to be subsequently retrieved in a search by another user, Lerman and Jones (2006) highlight the way in which Flickr users also find new images by browsing through their contacts' photostreams (social browsing).

Whilst tagging is seen as one of the main key success factors of Flickr, allowing multiple entry points to the retrieval of images, two further success factors will also be discussed: Flickr's groups, games, and competitions feature; and its Application Programming Interface (API).

\subsection{Groups, games, and competitions}

It is not obligatory that users of Flickr must join groups, indeed it tends to be more committed members that do so (Cox, Clough and Siersdorfer 2011). However, the Groups feature is one of the flagship features of Flickr and has contributed to its success (Negoescu et al. 2009). In Flickr, groups are where users who share a common interest come together to share images and have discussions, and many sub-cultures exist within Flickr groups (Cox 2008a).

Groups can be public (whereby anyone can see the photos within the group), publicinvitation only (whereby an existing member of the group must send an invitation), and private (whereby the group would not show up in any searches, and again, an existing member would need to send an invite).

Sharing images with groups on Flickr was considered to be an important part of Flickr etiquette, although it has been claimed that $50 \%$ of Flickr users never post images to groups (Negoescu and Gatica-Perez 2008), and research by Stvilia and Jörgensen (2010) found that from their sample of Flickr users, 37\% did not belong to any groups. Cox, Clough, and Siersdorfer (2011) in an investigation of 1,000 random Flickr groups found that nearly $80 \%$ of groups had less than 100 members, with nearly $50 \%$ of groups having less than 100 photos. However, it tends to be the comments that are attached to photos that are the means of interaction between group members, rather than general group discussions (Cox, Clough and Siersdorfer 2011). Such is the cohesion in many groups that users come to view them as additional online communities (Holmes and Cox 2011). Images posted to groups also receive more exposure (Negoescu and Gatica-Perez 2008) and are therefore more likely to be added to people's favorites and are more likely to receive comments and feedback from other members of the group. 
Related to Flickr's Groups features are the many games and competitions that take place. These games and competitions tend to occur within a specific group that has been set up, and the overarching idea is to have fun while playing around with images (Mäyrä 2011), and for 'awards' to be given to images that fulfill a certain criterion (Cox, Clough and Siersdorfer 2011). For example, in a "catch me if you can" game, an image submitted needs to match a previous image based on a specified attribute such as colour, shape, genre etc, and then the challenge passes along the line to another person (Mäyrä 2011). One of the most well-known games on Flickr is Photoshop Tennis where two players successively edit the same image (Cox 2008b) using graphics software (McDonald 2007). Such 'edits' may include: the addition of a figure or object into the picture; changing the head of a person in the image for another person's head; changing colours; editing objects; or to zoom out, whereby the image as it currently stands then becomes the cover of a book or the picture on a TV screen contained within a completely new image (Cox 2008b). Photoshop Tennis has no winners or losers or awards given for the 'best image' created (although players can receive positive feedback and accolade via comments received), the main purpose of the contest is to collaboratively create images and to have fun (Flickr 2007).

\subsection{Application Programming Interface (API)}

The Flickr Application Programming Interface (API) allows Flickr users to access and interact with data on the Flickr website (Anderson 2007). The API can therefore be seen as an important information retrieval mechanism on Flickr, allowing users to retrieve and download vast amounts of images, and data relating to images and users. Whilst other photo sharing sites also had APIs available at the same time as Flickr (e.g., SmugMug, Photobucket), Flickr provided the most comprehensive documentation to accompany its API, thus making it more accessible to people. McWilliams (2008) also described the Flickr API as 'the web services standard by which other APls should be judged.'

The API proved to be invaluable for academic researchers that have needed to interrogate data such as: image and tag information (Lerman and Jones 2006; Lerman,

Plangprasopchok and Wong 2007; van Zwol 2007; Prieur et al. 2008; Angus, Thelwall and Stuart 2008; Angus, Stuart and Thelwall 2010; Cox, Clough and Siersdorfer 2010; Dotan and Zaphiris 2010; Rorissa 2010, Stuart 2012) and user information (Mislove et al. 2008; Negoescu and Gatica-Perez 2008; Nov, Naaman and Ye 2008). The API has also been used to automatically add machine tags to images (McWilliams 2008), and also to create novel mash-ups such as earth album (a combination of Google Maps and Flickr images: www.earthalbum.com), and InfiniteComic (locates tweets and Flickr images based on supplied keywords and turns them into a comic strip: infinitecomic.com).

\subsection{Flickr users and motivation}

\subsection{Flickr users}

Cox (2008a) describes Flickr as encompassing all forms of photography: from people who could be defined as 'snapshooters' or casual hobbyists (those taking photos for friends and family, often of touristic travel and the mundane); to people who would class themselves as serious amateurs or serious hobbyists (those with a wider audience of hobby contacts, and a shift in photo content away from personal interest to presenting a sample of 'good' photos); through to semi-professional and professional photographers (those who have had formal photographic training and generally use photography as part of their job(s)).

Flickr is also widely used by a number of different organizations and cultural institutions. With one of the most notable being The Library of Congress. The Library of Congress have collaborated with Flickr to create 'The Commons', whereby images from cultural heritage institutions that have no known copyright restrictions can be shared, and Flickr users are invited to add tags and comments to the images (Springer et al. 2008). Allowing Flickr users to add tags and descriptions overcomes the problem of time-starved library staff having to annotate immense collections of images (Earle 2014). Therefore, this kind 
of collaboration is particularly important for 'making historical and special format materials easier to find in order to be useful for educational and other pursuits' (Springer et al. 2008). This has sparked a number of other museums, libraries and archives to adopt similar practices using 'The Commons' in order to also increase awareness and discoverability of their collections, with the Smithsonian being another notable institution that uses Flickr (Kalfatovic et al. 2008).

In an investigation of 52 cultural heritage institutes that have Flickr accounts, Beaudoin and Bosshard (2012) found that the predominant reason for using Flickr was to provide access to the images in their collections, and in many instances the institutions also thought that using Flickr provided a better technical experience than placing their images into an in-house content management system, 'providing the institution increased image storage capabilities, the ability to use their posted images in widgets and apps, and the service's ease of use.' However, in terms of the types of images that the institutions actually posted to Flickr, it was found that over half of the images analysed were related to disseminating information about current events and exhibitions occurring rather than being images from the institutions' collections.

\subsection{Motivations for uploading to Flickr}

In 2015 Flickr announced they had over 10 billion images on their site (Smith 2018), and therefore in addition to understanding the system features that have contributed towards Flickr's success, it is also important to understand why so many people want to put their images on Flickr. Whilst people may be drawn to a website because of innovative features such as tagging and groups, there has to be a greater internal motivation at play when the use of that website ultimately involves sharing one's images with friends, family, and potentially the general public.

Ames and Naaman (2007) developed a taxonomy of motivations for tagging images in systems such as Flickr, and this taxonomy includes four overarching categories that much of the literature on motivations for using web 2.0 systems also fits into, as well as the literature on the motivation to tag. The four overarching categories proposed by Ames and Naaman (2007) are: self-organisation, self-communication, social-organisation, and social-communication.

Motivation based on self-organisation is the drive to use Flickr as a place to store and organise photographs, either for long-term backup, or as a way of being able to easily access them at a future point. The fact that users of a site such as Flickr also 'own' the content they are uploading (compared to sites where external information is merely being shared), is also likely to have implications on motivation and people are therefore far more likely to be interested in managing and preserving their content (Nov, Naaman and Ye 2009). In addition, as more images are now being taken with cameraphones, many people worry that the images on their cameraphones will be lost when their phones are updated or upgraded, and so this is also a driving factor for uploading images to sites such as Flickr (David 2010). This is mirrored in the fact that the Apple iPhone is still the most popular camera for uploading images to Flickr (Stapley 2017).

Motivation based on self-communication is centered around the desire to keep track of and document day-to-day life or one's own development in a particular area (Ames and Naaman 2007).

Social-organisation is the motivation to use Flickr in order to allow other people to see the images that have been uploaded. This could be to allow absent friends and family to keep up to date with one's life. Or it could be to share images with people who have shared a mutual experience, such as attending a wedding, or party, or even a conference or workbased event (Kindberg et al. 2005a, 2005b). There is also the notion of 'passive' contact with people, whereby people share and view photos online because it is nice to see what certain people are up to, but without the expectation of commenting or liking photos (Lin and Faste 2012). 
Social-communication is the motivation to upload images to Flickr in the hope of drawing attention to them in order to gain likes, comments, feedback, accolades, or maybe even payment for the images in the hope they are licensed (Ames and Naaman 2007; Angus and Thelwall 2010). Images could also be uploaded as a conduit for connecting with other like-minded people who share similar interests or hobbies (Cox, Clough and Marlow 2008). Social-communication also covers motivations relating to self-expression and selfpresentation (e.g., using Flickr to present an overall image of oneself, and to express one's views and feelings) (Ames and Naaman 2007).

Stuart (2012), utilizing the framework proposed by Ames and Naaman (2007) conducted an investigation of 456 random Flickr users and asked why they upload their images to Flickr. The most popular reason cited via the use of a semi-structured survey was socialcommunication (31.75\%), and this was for respondents who had expressed one sole reason for using Flickr. More specifically, social signaling/attention was expressed as the main motivating factor, whereby respondents were keen to receive advice and feedback on the photos they had uploaded in the hope of improving their photography techniques. Self-communication was the least popular motivating factor, with only 12 respondents reporting using Flickr solely for this purpose.

Linked to the motivation that some people upload their images to Flickr in the hope of attaining commercial gain from them (Angus and Thelwall 2010) is the fact that between 2008 and 2014, Flickr had a partnership with Getty Images (the stock photo agency). This partnership allowed Getty to contact photographers via Flickr if they wanted to pay to license their images. The partnership was extremely successful, with over 400,000 images being selected for commercial use (Galai 2014). In 2014 this partnership came to an end, with no suggestion that it is likely to be renewed (Bowker 2017), signaling that Getty Images does not perhaps view its relationship with Flickr in as high a regard as it once did.

\subsection{Failure to transform}

After an inspection of articles written about Flickr since its decline in popularity, three main contributing factors seem to reoccur when discussing its decrease in popularity: the company's acquisition with Yahoo; its failure to implement a successful mobile platform; and the advent of new image-centric smartphone applications such as Instagram and Snapchat.

Flickr was bought by Yahoo in 2005, and in the two years following its acquisition it went from strength to strength However, whereas Flickr had initially started out as a company that had paved the way for innovative new features, its innovation slowly began to stagnate after the acquisition. 'All Yahoo cared about was the database its users had built and tagged. It didn't care about the community that had created it or (more importantly) continuing to grow that community by introducing new features' (Honan 2012). Flickr staff had to spend a lot of time on things related to the acquisition and in making sure that certain demands of the acquisition were being met, and this therefore hampered their ability to spend time on creating innovative new features. As a result of this, Flickr missed the perfect window of opportunity for introducing a successful mobile platform. Infact, Flickr's mobile platform only became fully operational in 2017 (Flickr 2017). This missed opportunity meant that Flickr became difficult for users to access via their smartphones (Bowker 2017), at the exact time when smartphone usage was booming. By 2015, two thirds of the UK population owned a smartphone, with 33\% preferring to use their smartphones for accessing online content rather than laptops and desktop computers (Ofcom 2015). This rise in the use of smartphone usage also went hand in hand with the growth of smartphone photography. The fact that people carry their smartphones with them everywhere they go means that they are always 'at hand' for capturing photos, and by $2009,67 \%$ of UK households were using their smartphones as their main camera to take pictures with (Dutton, Helsper and Gerber 2009, 13). 
Whereas taking a photograph was once generally set aside for special events such as weddings, christenings, birthdays, holidays, and family portraits (Murray 2008),

photographs are now increasingly being taken of the more mundane aspects of everyday life (Okabe 2004), as well as increasing numbers of selfies (Walker 2005; Kedzior, Allen and Schroeder 2016). Whilst 'mundane' photographs and 'selfies' aren't as likely to make it into the prized family album, they are however more likely to be shared with friends and family in a more fleeting way, to generate humour among friends and family (Meyer 2008), to let loved ones know they are being thought of, or to add to personal common ground with someone (Kindberg et al., 2005a, 2005b), and this kind of photography exchange lends itself perfectly to the mobile platform.

Sharing images via MMS was slow to take off for two main reasons: firstly, most people tended to have pay as you go phones at that time and MMS messages were more expensive to send than a normal text message; secondly, in order for an MMS to be successfully received, the recipient often had to have the same type of phone as the sender (Economist 2006). But with the arrival of more affordable monthly phone contracts, people began to increasingly have data plans that allowed them time to connect to the web (Stuart 2013). Therefore, people began to upload their images to social networking sites such as Facebook and Flickr, and more recently via image-centric social media apps such as Instagram and Snapchat.

Instagram is a photo and video-sharing network that was launched in 2010, and Snapchat is a multimedia messaging app that was launched in 2011. The core aspect of both of these apps is that they are designed for sharing images captured on someone's smartphone in a quick and engaging way. Indeed, Snapchat's main feature is centered around the fact that images quickly disappear on a recipient's handset once they have been viewed, thus positioning the app as the perfect conduit for sharing those 'mundane' and fleeting photographs that have limited appeal for long term archiving. Instagram images can have filters applied to them, which can drastically change the look and feel of an image, transforming a bad image into one that is more aesthetically pleasing. Such is the appeal of these apps that it is now often claimed that the future of photography lies in cameraphone apps (Eler 2012).

It is especially bittersweet that image-centric social media apps such as Instagram and Snapchat have usurped a lot of attention away from Flickr for the sharing of images and videos, as it was Flickr that was originally a forerunner in the more nuanced aspects of social networking. Flickr allowed for contacts to be marked as friends or family, and images could be shared with friends, family, or just a few specific friends and family, they could also be shared with the public at large, or they could be marked as entirely private. This is a more complex form of networking compared to the more binary relationships seen in Instagram, where someone either is or isn't a contact, and content is either shared with the public at large, or only with one's contact list if the user's account is set to private (Honan 2012). Flickr has been usurped at something it paved the way in.

We live in an increasingly visual world, and digital images are a ubiquitous part of everyday life (Jörgensen 2016), it therefore follows suit that even people who do not class themselves as photographers nonetheless enjoy taking and sharing images. As such, apps such as Instagram and Snapchat are more likely to appeal to such people due to their ease and simplicity. In many ways, Flickr was a placeholder, satisfying the desire that people had to showcase the increased number of images that they were now taking on their smartphones, and once a platform came along that was more specifically designed for the layman image taker rather than the aspiring photographer, they jumped ship. It seems unlikely that these people will ever return to Flickr.

\subsection{The future}

In April 2018 it was announced that Flickr has gone through another acquisition, with Yahoo (who themselves were acquired by Verizon/Oath in 2017) selling Flickr to fellow 
photo sharing and hosting site SmugMug (Flickr 2018). Initial responses to the acquisition have been positive, with Flickr's original creators Stewart Butterfield and Caterina Flake giving the thumbs up (Hawk 2018). The main reason behind the positive response being that companies such as Yahoo/Verizon/Oath have different priorities when it comes to thinking about the users of Flickr compared to SmugMug. A company such as Verizon/Oath is a multinational telecommunications conglomerate, whereas SmugMug is a fellow image sharing and hosting site (Hawk 2018). Whilst SmugMug is a paid for service that focuses on catering to semi-pro and professional photographers rather than social networking (Fleishman 2018), Flickr on the other hand (in addition to its paid for pro account option) also offers free accounts that come with 1TB of storage. However, SmugMug is nonetheless a site that is passionate about photography, and that is a crucial difference when compared to Yahoo and Verizon/Oath.

One of the reasons attributed to Flickr's demise was its failure to develop a successful mobile platform, and SmugMug's CEO Don MacAskill already has ideas about how the mobile app can be improved (Fleishman 2018). The introduction of image-centric mobile apps such as Instagram and Snapchat have also been seen to contribute towards Flickr's demise, however, MacAskill does not intend to try to compete with such apps. This is actually a smart move. It is unlikely that people who do not class themselves as photographers or aspiring photographers will return to Flickr, because apps such as Instagram and Snapchat fulfill their needs for a fun way to share their images in a much more instant way. Flickr is a more complex system, aimed at photographers, with more sophisticated image editing capabilities, and more opportunities for social networking related specifically to photography. MacAskill recognizes these differences, and rather than try to compete, he sees SmugMug and Flickr as a safe place for photographers to 'do anything they want to do with their work', with the ultimate aim being to create the technology that allows photographers to create the images that they want to create (Fleishman 2018).

Spiteri and Rasmussen Pennington (2018) advise that, 'the internet is moving rapidly from the social web embodied in Web 2.0, to the semantic web (Web 3.0), where information resources are linked in such a way as to make them comprehensible to both machines and humans.' If machines can more easily understand information resources, they will be able to 'build relationships between resources, enrich users' experience and improve discoverability' (Cagnazzo 2018). Using an example put forward by Choudhury, Breslin and Passant (2009), who explain that for resources tagged with terms such as 'New York city, nyc and big apple, using one of the tags will only retrieve resources tagged with the exact match.' Whereas if all of the tags could be linked to the same concept (uniquely identified by a URI), then all images that were tagged with at least one of the terms would all be subsequently retrieved. Linking tags to URIs solves the issue of ambiguity, as tags are linked to unambiguous URIs (Cagnazzo 2018).

There have been numerous studies already that have proposed semi-automatic image annotation systems that have attempted to enrich Flickr tags with semantic relationships (Rattenbury, Good and Naaman 2007; Becker and Bizer 2009; Im and Park 2014). Authors tend to caveat however that human assessment will always be needed in conjunction with semi-automated systems, as evidenced by the introduction of Flickr's controversial auto-tagging feature in 2015 . The same is likely to be true for the automatic addition of semantic tags. While semantic tags may be more accurate, and users may be given the option of which tags to include from a suggestion pool, it nonetheless remains that the average Flickr user is likely to be uninterested in employing the use of semantic tags, despite any benefits for future search and retrieval. Although, SmugMug could potentially persuade those photographers who are particularly keen to have their images found to adopt semantic tagging (perhaps via the use of a dedicated Flickr plugin, meaning that not all Flickr users would have semantic tagging forced upon them). SmugMug could highlight the benefits of semantic tagging in terms of search and retrieval and leave it up to the users to decide whether or not to use it. 


\subsection{Conclusions for knowledge organization}

With reference to knowledge retrieval, and the fact that Flickr users may not necessarily search for images using the same search terms as those assigned by the image uploader, Cox (2008a) posits that most Flickr users are not likely to be searching Flickr with a specific 'information need', and are instead likely to be browsing for visual pleasure, thus rendering precision and recall as irrelevant. This therefore creates a very different knowledge organization landscape than traditional classification indexing in specialist picture libraries and databases.

Findability is nonetheless still an important aspect of a site as large as Flickr, and tagging remains the dominant method of retrieving images. The section on tagging highlighted some of the problems inherent with tagging, and how it is these problems with tags that negatively affect their role in an information retrieval environment (Kim et al. 2008). Whilst the adoption of semantic tagging (tagging content with URIs) is seen as a way of overcoming some of the problems inherent with user-generated tags, semantic web requirements can often seem intimidating, and more user-friendly interfaces are needed (Cagnazzo 2018). As Flickr has always been a website that has been revered for its savvy design and easy to use interfaces (Tik 2005), it has the perfect vantage point to try to persuade at least some users to adopt semantic tagging. Professional and semiprofessional photographers who are particularly keen to have their images found may be the user demographic who are most likely to be persuaded of the benefits of semantic tagging.

However, now that Flickr has been acquired by SmugMug, with their emphasis firmly placed on the role of the photographer rather than on profits, there is hope that Flickr will continue to grow its position as the biggest repository of images on the internet. With such a big repository of images, comes a level of responsibility with regards to the content of the images stored within the system. Websites that become big and successful become arbiter in deciding what is and isn't allowed on their systems. For social sites that become very successful, this has important political and societal implications, as it is the worldview of the sites owners that can begin to dictate the type of content that is allowed on the site. This can be reflected in controversy in 2018 surrounding Facebook's co-founder Mark Zuckerberg who was accused of censoring content from Republican vloggers (Robertson 2018). Flickr has to be mindful about its approach to image censorship in order to achieve the right balance between protecting its user base and allowing freedom of expression.

Ultimately, Flickr's main weapons for rising back up the popularity ranks are ones that were executed perfectly before Yahoo/Verizon/Oath came along, and that was adapting quickly in the current internet age and listening to feedback from its loyal fan base. Now that Flickr has joined forces with SmugMug, it is envisaged that Flickr users will once again be placed at the forefront of any future endeavors.

\subsection{References}

Ames, Morgan, Dean Eckles, Mor Naaman, Mirjana Spasojevic, and Nancy Van House. 2010. "Requirements for Mobile Photoware." Personal and Ubiquitous Computing 14, no. 2: 95-109.

Ames, Morgan, and Mor Naaman. 2007. "Why We Tag: Motivations for Annotation in Mobile and Online Media." Proceedings of the SIGCHI Conference on Human Factors in Computing Systems, April 28 - May 3, San Jose, California, USA. ACM. 971 - 980.

Anderson, Paul. 2007. "What is Web 2.0? Ideas, Technologies and Implications for Education." JISC Technology and Standards Watch, February, http://www.jisc.ac.uk/media/documents/techwatch/tsw0701b.pdf

Angus, Emma, David Stuart, and Mike Thelwall. 2010. "Flickr's Potential as an Academic Image Resource: An Exploratory Study." Journal of Librarianship and Information Science 42, no. $4: 268-278$. 
Angus, Emma, and Mike Thelwall. 2010. "Motivations for Image Publishing and Tagging on Flickr." Proceedings of the 14th International Conference on Electronic Publishing, June 16 - 18, Helsinki, Finland. In Turid Hedlund and Yasar Tonta (eds). Helsinki: Hanken School of Economics, 189-204.

Angus, Emma, Mike Thelwall, and David Stuart. 2008. "General Patterns of Tag Usage in Flickr Image Groups.” Online Information Review 32, no. 1: 89-101.

Aurnhammer, Melanie, Peter Hanappe, and Luc Steels. 2006. "Integrating Collaborative Tagging and Emergent Semantics for Image Retrieval." Paper presented at the World Wide Web Conference, May 23 - 26, Edinburgh, UK. http://hdl.handle.net/10261/127833

Barton, David. 2015. "Tagging on Flickr as a Social Practice." In Rodney Jones, Alice Chik, and Christoph A. Hafner. (eds), Discourse and Digital Practices: Doing Discourse Analysis in the Digital Age. New York, USA: Routledge. 48-65.

Bausch, Paul, and Jim Bumgardner. 2006. Flickr Hacks: Tips and Tools for Sharing Photos Online. Sebastopol, CA. USA: O'Reilly Media Inc.

Beaudoin, Joan.E. and Cécile Bosshard. 2012. "Flickr Images: What \& Why Museums Share." Proceedings of the American Society for Information Science and Technology, October 28 - 30, Baltimore, MD. USA. 49, no. 1: 1-7.

Becker, Christian, and Chris Bizer. 2009. Flickr Wrappr http://wifo5-03.informatik.unimannheim. de/flickrwrappr/

Berinstein, Paula. 1996. Finding Images Online: Online User's Guide to Image Searching in Cyberspace. Wilton, CT., USA: Pemberton Press.

Bowker, Daniela. 2017. "Flickr is on its Way Out. What Are Your Alternatives?" DIY Photography https://www.diyphotography.net/flickr-way-alternatives/

Cagnazzo, Laura. 2018. "Tagging the Semantic Web: Combining Web 2.0 and Web 3.0." In Louise Spiteri and Diane Pennington (eds), Social Tagging in a Linked Data Environment. London, UK: Facet Publishing. 11-38.

Cox, Andrew M. 2008a. "Flickr: A Case Study of Web 2.0." Aslib Proceedings 60, no. 5: 493-516.

Cox, Andrew M. 2008b. "The Shaping of Mass Participation in Web 2.0: Photoshop Contest on Flickr." Paper presented at the Association of Internet Researchers Conference (AolR), October 15 - 18, Copenhagen, Denmark.

Cox, Andrew M, Paul Clough, and Jennifer Marlow. 2008. "Flickr: A First Look at User Behaviour in the Context of Photography As Serious Leisure." Information Research 13, no. 1: http://informationr.net/ir/13-1/paper336.html

Cox, Andrew M, Paul Clough, and Stefan Siersdorfer. 2010. "Developing Metrics to Characterize Flickr Groups." Journal of the American Society for Information Science and Technology 62, no. 3: 493-506.

David, Gaby. 2010. "Camera Phone Images, Videos and Live Streaming: A Contemporary Visual Trend." Visual Studies 25, no. 1: 89-98.

Ding, Ying, Elin K. Jacob, Zhixiong Zhang, Schubert Foo, Erjia Yan, Nicolas L. George, and Lijiang Guo. 2009. "Perspectives on Social Tagging." Journal of the American Society for Information Science and Technology 60, no. 12: 2388-2401. 
Dotan, Amir, and Panayiotis Zaphiris. 2010. "A Cross-Cultural Analysis of Flickr Users from Peru, Israel, Iran, Taiwan and the UK." International Journal of Web Based Communities 6, no. 3: 284-302.

Dutton, William H, Ellen J. Helsper, and Monica M. Gerber. 2009. The Internet in Britain: 2009. Oxford, UK: Oxford Internet Institute, University of Oxford.

Eakins, John P, and Margaret E. Graham. 1999. "Content-based Image Retrieval: A Report to the JISC Technology Applications Programme." University of Northumbria at Newcastle: Institute for Image Data Research.

http://www.leeds.ac.uk/educol/documents/00001240.htm

Earle, Evan., 2014. "Crowdsourcing Metadata for Library and Museum Collections Using a Taxonomy of Flickr User Behavior." Masters Thesis. Cornell University, New York, USA. Economist. 2006. "Lack of Text Appeal." Economist 380(8489): 56.

Eler, Alicia. 2012. "Flickr Can't Go Back to What it Once Was." Readwrite, February 22, 2012. http://www.readwriteweb.com/archives/flickr_cant_go_back_to_what_it_once_was/

Etherington, Darrell. 2014. "Flickr at 10: 1M Photos Shared Per Day, 170\% Increase Since Making 1TB Free." https://techcrunch.com/2014/02/10/flickr-at-10-1m-photos-shared-perday170-increase-since-making-1tb-free/.

Fleishman, Glenn. 2018. "Yes, Flickr Has a Future - As "A Safe Place for Photographers." https://www.fastcompany.com/40563632/yes-flickr-has-a-future-as-a-safe-place-forphotographers

Flickr. 2007. "Photoshop Tennis." Flickr, https://www.flickr.com/groups/pstennis/

Flickr. 2010. “5,000,000,000.” Flickr blog, September 19, 2010, http://blog.flickr.net/en/2010/09/19/5000000000/

Flickr. 2017. "Making Flickr Fully Responsive." Flickr blog, April 18, 2017, http://blog.flickr.net/en/2017/04/18/making-flickr-fully-responsive/

Flickr. 2018. "Together is Where Photographers Belong!" Flickr blog, April 20, 2018, https://blog.flickr.net/en/2018/04/20/together-smugmug-flickr/

Galai, Noam. 2014. "Getty Images Announces the Termination of Their Partnership with Flickr. Fstoppers." March 11, 2014, https://fstoppers.com/stock/getty-imagesannouncestermination-their-partnership-flickr-7998

Golder, Scott A, and Bernardo A. Huberman. 2006. "Usage Patterns of Collaborative Tagging Systems." Journal of Information Science 32, no. 2: 198-208.

Google Trends. 2018. https://trends.google.com/trends/explore?date=all\&q=web\%202.0/

Graham, Margaret. E. 2001. "The Cataloguing and Indexing of Images: Time for a New Paradigm?” Art Libraries Journal, 26, no. 1: 22-27.

Guy, Marieke, and Emma Tonkin. 2006. "Folksonomies: Tidying Up Tags?" D-Lib Magazine 12(1): http://www.dlib.org/dlib/january06/guy/01guy.html

Hammond, Tony, Timo Hannay, Ben Lund, and Joanna Scott. 2005. "Social Bookmarking Tools (I): A General Review." D-Lib Magazine no. 11: 1-22.

Hawk, Thomas. 2018. "My Thoughts on the SmugMug Flickr Acquisition." PetaPixel, April 21, 2018, https://petapixel.com/2018/04/21/thoughts-on-the-smugmug-flickr-acquisition/ 
Heckner, Markus, Michael Heilemann, and Christian Wolff. 2009. "Personal Information Management vs. Resource Sharing: Towards a Model of Information Behaviour in Social Tagging Systems." Paper presented at the Third International Conference for Weblogs and Social Media, May 17 - 20, San Jose, California, USA.

http://www.aaai.org/ocs/index.php/ICWSM/09/paper/download/212/407

Hern, Alex. 2015. “Flickr Faces Complaints Over 'Offensive' Auto-Tagging for Photos.” The Guardian, May 20, 2015, https://www.theguardian.com/technology/2015/may/20/flickr-complaints-offensive-autotaggingphotos

Holmes, Paul, and Andrew M. Cox. 2011. "'Every Group Carries the Flavour of the Admins': Leadership on Flickr." International Journal of Web Based Communities 7, no. 3: 376-391.

Honan, Mat. 2012. "How Yahoo Killed Flickr and Lost the Internet." Gizmodo, May 15, 2012, https://gizmodo.com/5910223/how-yahoo-killed-flickr-and-lost-the-internet

Im, Dong-Hyuk, and Geun-Duk Park. 2015. "Linked Tag: Image Annotation Using Semantic Relationships Between Image Tags." Multimedia Tools and Applications 74, no. 7: 2273-2287.

Jansen, Bernard J. 2008. "Searching for digital images on the web." Journal of Documentation 64, no. 1: 81-101.

Jörgensen, Corinne. 2003. Image Retrieval: Theory and Research. Lanham, MD., USA: Scarecrow.

Jörgensen, Corinne. 2016. "Photos: Flickr, Facebook and Other Social Networking Sites." In Allen Foster, and Pauline Rafferty, (eds), Managing Digital Cultural Objects: Analysis, discovery and retrieval. London, UK: Facet Publishing. 143-181.

Kalfatovic, Martin R, Effie Kapsalis, Katherine P. Spiess, Anne Van Camp, and Michael Edson. 2008. "Smithsonian Team Flickr: a Library, Archives, and Museums Collaboration in Web 2.0 Space." Archival science 8, no. 4: p.267.

Kedzior, Richard, Douglas E. Allen, and Jonathan Schroeder. 2016. "The Selfie Phenomenon-Consumer Identities in the Social Media Marketplace." European Journal of Marketing 50, no. 9/10: 1767-1772.

Kennedy, Lyndon, Mor Naaman, Shane Ahern, Rahul Nair, and Tye Rattenbury. 2007. "How Flickr Helps us Make Sense of the World: Context and Content in CommunityContributed Media Collections." Proceedings of the 15th ACM international conference on Multimedia, September 24 - 29, Augsburg, Germany. ACM. 631-640.

Kim, Eugene. 2014. "The Guy Who's Trying to Build the Next Microsoft Wrote This Epic Resignation Letter When He Left Yahoo." Business Insider, August 7, 2014, http://www.businessinsider.com/stewart-butterfield-epic-resignation-letter-2014-8?IR=T

Kim, Hak Lae, Alexandre Passant, John G. Breslin, Simon Scerri, and Stefan Decker. 2008. "Review and Alignment of Tag Ontologies for Semantically-linked Data in Collaborative Tagging Spaces". In Semantic Computing 2008 IEEE International Conference on Semantic Computing. August 4 - 7, Santa Clara, CA. USA. IEEE. 315-322 
Kindberg, Tim, Mirjana Spasojevic, Rowanne Fleck, and Abigail Sellen. 2005b. "I Saw This and Thought of You: Some Social Uses of Camera Phones." Paper presented at the Conference on Human Factors in Computing Systems, April 2 - 7, Portland, Oregon, USA. DOI: 10.1145/1056808.1056962

Lerman, Kristina, and Laurie Jones. 2006. "Social Browsing on Flickr.” Paper presented at the International Conference on Weblogs and Social Media, March 26 - 28, Boulder, Colorado, USA. https://arxiv.org/abs/cs/0612047

Lerman, Kristina, Anon Plangprasopchok, and Chio Wong. 2007. "Personalizing Image Search Results on Flickr." Paper presented at the AAAI workshop on Intelligent Web Personalization, July 22 - 26, Vancouver, British Columbia, Canada.

https://arxiv.org/abs/0704.1676

Lin, Clifton, and Haakon Faste. 2012. "Image Exploration and Social Relationships." Paper presented at the Conference on Human Factors in Computing Systems, May $5-10$, Austin, Texas, USA. New York, NY, USA: ACM Press.

Macgregor, George, and Emma McCulloch. 2006. "Collaborative Tagging as a Knowledge Organisation and Resource Discovery Tool." Library Review 55, no. 5: 291-300.

Marlow, Cameron, Mor Naaman, danah boyd, and Marc Davis. 2006. "Position Paper, Tagging, Taxonomy, Flickr, Article, Toread." Paper presented at the World Wide Web Conference, May 23 - 26, Edinburgh, UK. https://www.danah.org/papers/WWW2006.pdf

Mathes, Adam. 2004. "Folksonomies - Cooperative Classification and Communication Through Shared Metadata." Computer Mediated Communication.

http://www.adammathes.com/academic/computer-mediatedcommunication/ folksonomies.html

Mäyrä, Frans. 2011. "Games in the Mobile Internet: Understanding Contextual Play in "Flickr" and "Facebook"' (pp. 108-129). In Garry Crawford, Victoria K Gosling, and Ben Light, (eds), Online Gaming in Context: The social and cultural significance of online games. London, UK: Routledge.

McDonald, David. W. 2007. "Visual Conversation Styles in Web Communities." 40th Hawaii International International Conference on Systems Science (HICSS), January 3 6, Waikoloa, Big Island, HI, USA. DOI: 10.1109/HICSS.2007.605

McCracken, Harry. 2014. "Flickr Turns 10: The Rise, Fall, and Revival of a Photo-Sharing Community." Time, February 10, 2014. http://time.com/6855/flickr-turns-10-the-rise-fallandrevival-of-a-photo-sharing-community/

McWilliams, Jeremy. 2008. "Developing an Academic Image Collection with Flickr." The Code4Lib Journal (3): http://journal.code4lib.org/articles/74

Meyer, Eric. T. 2008. "Digital Photography." In Sigrid. Kelsey. and Kirk. St.Amant, (eds), Handbook of research on computer mediated communication (Vol. 1, 791-803.). Hershey, PA., USA: Information Science Reference.

Mislove, Alan, Hema S. Koppula, Krishna Gummadi, Peter Druschel, and Bobby Bhattacharjee. 2008. "Growth of the Flickr Social Network." Proceedings of the first workshop on Online social networks - ACM SIGCOMM Conference, August 18, Seattle, WA, USA. ACM. 25-30.

Morville, Peter. 2005. Ambient Findability: What We Find Changes Who We Become. Cambridge, UK: O'Reilly. 
Murray, Susan. 2008. "Digital Images, Photo-Sharing, and Our Shifting Notions of Everyday Aesthetics." Journal of Visual Culture 7, no. 2: 147-163.

Negoescu, Radu-Andrei, Brett Adams, Dinh Phung, Svetha Venkatesh, and Daniel Gatica-Perez. 2009. "Flickr Hypergroups." Paper presented at the ACM International Conference on Multimedia, October 19 - 24, Beijing, China. ACM. 813-816.

Negoescu, Radu-Andrei, and Daniel Gatica-Perez. 2008. “Analyzing Flickr Groups.” Paper presented at the ACM International Conference on Image and Video Retrieval, July 7 - 9, Ontario, Canada. ACM. 417-426.

Nov, Oded, Mor Naaman, and Chen Ye. 2009a. "Motivational, Structural and Tenure Factors that Impact Online Community Photo Sharing." Paper presented at the Third International Conference for Weblogs and Social Media, May 17 - 20, San Jose, California, USA. https://www.aaai.org/ocs/index.php/ICWSM/09/paper/viewFile/206/426

Nov, Oded, Mor Naaman, and Chen Ye. 2009b. "Analysis of Participation in an Online Photo-Sharing Community: A Multidimensional Perspective." Journal of the American Society for Information Science and Technology 61, no. 3: 433-637.

Ofcom. 2015. "The UK Is Now a Smartphone Society." August 6, 2015 https://www.ofcom.org.uk/about-ofcom/latest/media/media-releases/2015/cmr-uk-2015.

Okabe, Daisuke. 2004. "Emergent Social Practices, Situations and Relations Through Everyday Camera Phone Use." Paper presented at the The 2004 International Conference on Mobile Communication, October 18 -19, Seoul, Korea. http://www.itofisher.com/mito/archives/okabe_seoul.pdf

Prieur, Christophe, Dominique Cardon, Jean-Samuel Beuscart, Nicolas Pissard, and Pascal Pons. 2008. "The Strength of Weak Cooperation: A Case Study on Flickr." arXiv preprint. http://arxiv.org/abs/0802.2317

Rafferty, Pauline. 2016. "Managing, Searching and Finding Digital Cultural Objects: Putting it in Context." In Allen Foster, and Pauline Rafferty, (eds), Managing Digital Cultural Objects: Analysis, discovery and retrieval. London, UK: Facet Publishing. 3-23.

Rafferty, Pauline, and Rob Hidderley. 2007. "Flickr and Democratic Indexing: Dialogic Approaches to Indexing", Aslib Proceedings 59 nos 4/5: 397-410.

Rattenbury, Tye, Nathaniel Good, and Mor Naaman. 2007. "Towards Automatic Extraction of Event and Place Semantics from Flickr Tags." In SIGIR '07 Proceedings of the 30th Annual International ACM SIGIR Conference on Research and Development in Information Retrieval, July 23 - 27, Amsterdam, Netherlands. ACM. 103-10.

Robertson, Adi. 2018. "Republican lawmakers keep grilling mark Zuckerberg about 'censoring' two conservative vloggers." The Verge, April 11, 2018, https://www.theverge.com/2018/4/11/17225120/mark-zuckerberg-facebook-congresscruzblackburn-diamond-silk

Rorissa, Abebe. 2010. "A Comparative Study of Flickr Tags and Index Terms in a General Image Collection." Journal of the American Society for Information Science and Technology, 61, no. 11: 2230-2242.

Shirky, Clay. 2005, "Ontology is Overrated: Categories, Links, Tags", http://shirky.com/writings/ontology_overrated.html

Sigurbjörnsson, Börkur, and Roelof van Zwol. 2008. "Flickr Tag Recommendation Based on Collective Knowledge." Paper presented at the World Wide Web Conference, April 21 
- 27, 2008, Beijing, China. ACM. 327-336.

Smith, Craig. 2018. "17 Interesting Flickr Stats and Facts (February 2018) by the Numbers." Digital Marketing Ramblings, February 3, 2018.

https://expandedramblings.com/index.php/flickr-stats/

Smith, Gene. 2008. Tagging: People Powered Metadata for the Social Web. Berkeley, California: New Riders.

Soergel, Dagobert. 2009. "Digital Libraries and Knowledge Organization". In Sebastian Ryszard Kruk and Bill McDaniel, eds., Semantic Digital Libraries. Berlin: Springer, 9-39.

Spiteri, Louise. F. 2007. "The Structure and Form of Folksonomy Tags: The Road to the Public Library Catalog." Information technology and libraries 26, no. 3: 13-25.

Spiteri, Louise, and Diane Pennington. 2018. "Introduction: The Continuing Evolution of Social Tagging." In Social Tagging in a Linked Data Environment. London, UK: Facet Publishing. 1-10.

Springer, Michelle, Beth Dulabahn, Phil Michel, Barbara Natanson, David Reser, David Woodward, and Helena Zinkham. 2008. "For the Common Good: The Library of Congress Flickr Pilot Project." Washington, DC, Library of Congress,

https://www.loc.gov/rr/print/flickr_report_final.pdf

Stapley, Jon. 2017. "Flickr Announces its Most Popular Cameras in 2017." Digital Camera World, December 11, 2017, https://www.digitalcameraworld.com/news/flickr-announcesitsmost-popular-cameras-in-2017

Stuart, Emma. 2012. "Motivations to Upload and Tag Images vs Tagging Practice: An Investigation of The Web 2.0 Site Flickr." PhD thesis. University of Wolverhampton, Wolverhampton, UK.

Stuart, Emma. 2013. "Organizing Photographs: Past and Present." In Jung-ran Park and Lynne Howarth, (eds), New Directions in Information Organization. Emerald Library and Information Science Book Series. 137-155.

Stvilia, Besiki, and Corinne Jörgensen. 2010. "Member Activities and Quality of Tags in a Collection of Historical Photographs in Flickr." Journal of the American Society for Information Science and Technology 61, no. 12: 2477-2489.

Terras, Melissa. 2008. Digital images for the information professional. Hampshire: Ashgate Publishing Limited.

Tik, Jan. 2005. "Why is Flickr So Successful." Flickr Central, May 20, 2005, https://www.flickr.com/groups/central/discuss/36512/

Van House, Nancy. 2007. "Flickr and Public Image Sharing: Distant Closeness and Photo Exhibition." Paper presented at the Conference on Human Factors in Computing Systems, April 28 - May 3, San Jose, California, USA. ACM. 2717-2722.

Van House, Nancy, Marc Davis, Morgan Ames, Megan Finn, and Vijay Viswanathan. 2005. "The Uses of Personal Networked Digital Imaging: An Empirical Study of Cameraphone Photos and Sharing." Paper presented at the Conference on Human Factors in Computing Systems, April 2 - 7, Portland, Oregon, USA. ACM. 1853-1856.

Van House, Nancy, Marc Davis, Yuri Takhteyev, Morgan Ames, and Megan Finn. 2004. "The Social Uses of Personal Photography: Methods for Projecting Future Imaging Applications." University of California, Berkeley, Working Papers. 
http://people.ischool.berkeley.edu/ vanhouse/photo_project/pubs/vanhouse_et_al_2004b. pdf

van Zwol, Roelof. 2007. "Flickr: Who is looking?" Paper presented at the ACM International Conference on Web Intelligence, November 2 - 5, Silicon Valley, CA, USA. IEEE Computer Society. 184-190.

Walker, Jill. 2005. "Mirrors and Shadows: The Digital Aesthicisation of Oneself." Proceedings Digital Arts and Culture 2005, December 1 -3, Copenhagen, Denmark. https://bora.uib.no/handle/1956/1136

Weinberger, David. 2007. Everything is Miscellaneous: The Power of the New Digital Disorder. New York, NY: Times Books.

Wilkinson, David. 2007. Flickr Mashups. Indiana, USA: Wiley Publishing, Inc.

Wray, Richard, and Bobbie Johnson. 2008. "I'm Off to Tend My Alpacas - Flickr Founder's Exit Marks End of a Web Era", June 20, 2008, The Guardian, https://www.theguardian.com/media/2008/jun/20/digitalmedia.yahoo

Xu, Zhichen, Yun Fu, Jianchang Mao, and Difu Su. 2006. "Towards the Semantic Web: Collaborative Tag Suggestions." Paper presented at the World Wide Web Conference, May 23 - 26, Edinburgh, UK.

http://www.ambuehler.ethz.ch/CDstore/www2006/www.rawsugar.com/www2006/13.pdf

Zollers, Alla. 2007. "Emerging Motivations for Tagging: Expression, Performance, and Activism." Paper presented at the World Wide Web Conference, May 8 - 12, Banff, Alberta, Canada. http://wwwconference.org/www2007/workshops/paper_55.pdf 